DOI: $10.5216 /$ rs.v5.65952

\title{
FORMAÇÃO DO PROFESSOR NA UNIVERSIDADE FEDERAL RURAL DA AMAZÔNIA: CONTRIBUIÇÕES DA DISCIPLINA DE LIBRAS
}

\author{
TEACHER TRAINING AT THE UNIVERSIDADE FEDERAL RURAL DA \\ AMAZÔNIA: CONTRIBUTIONS FROM THE SUBJECT OF LIBRAS
}

\author{
Leila Cristina Silva da Silva* \\ Juliana Guimarães Faria** \\ Soraya Bianca Reis Duarte***
}

\section{Resumo}

Este trabalho trata de um mapeamento da implementação da disciplina de Língua Brasileira de Sinais (Libras) na Universidade Federal Rural da Amazônia (UFRA), com o objetivo de investigar como ocorre a oferta da disciplina nos cursos de Licenciatura dessa instituição. Na perspectiva de refletir sobre a disciplina de Libras e sua contribuição para a formação do professor, são analisadas as ementas da disciplina, as cargas horárias e as referências presentes nos Projetos Pedagógicos dos Cursos de Graduação da UFRA. O levantamento dos dados foi realizado mediante buscas no site oficial da instituição. Os resultados apontam que os cursos de Licenciatura ofertam a disciplina de Libras como obrigatória e com carga horária ampliada em relação aos cursos de bacharelado, que ofertam a disciplina de forma eletiva e com carga horária menor. Apontam, ainda, que não há variação significativa de conteúdos das ementas entre os cursos de licenciatura e bacharelado, desconsiderando-se as especificidades de cada um deles.

Palavra-chave: Libras. Disciplina. Licenciatura. Formação do professor.

\section{Introdução}

A implementação da disciplina de Língua Brasileira de Sinais (Libras) nos cursos de Licenciatura no Brasil, com vistas à formação do professor, é um tema atual e perpassa reflexões sobre o bilinguismo, sobretudo, em se tratando do processo de ensinoaprendizagem de alunos surdos. A sua oferta em cursos de formação de professores é uma

\footnotetext{
* Universidade Federal Rural da Amazônia (UFRA), Belém, Pará, Brasil. E-mail: leila.cchaves@outlook.com

** Universidade Federal de Goiás (UFG), Goiânia, Goiás, Brasil. E-mail: julianagf@ufg.br

*** Instituto Federal de Educação, Ciência e Tecnologias de Goiás (IFG), Goiânia, Goiás, Brasil. E-mail: sorayabianca@gmail.com
} 
obrigatoriedade, discriminada na Lei da Libras, 10.436/2002 (BRASIL, 2002) e regulamentada no Decreto 5.626/2005 (BRASIL, 2005).

Em decorrência disso, compreendemos que novas exigências permeiam esse tipo de formação, criando novos arranjos que afetam o processo formativo, envolvendo tanto o professor e sua prática docente quanto os alunos surdos e suas formas de aprender. Almeida (2012, p. 70) ressalta, em outras palavras, que isso

\begin{abstract}
[...] requer também a atenção aos processos formativos que mobilizem os saberes das teorias educacionais necessários à compreensão da prática docente, capazes de desenvolver os conhecimentos e as habilidades para que os professores avaliem e investiguem a própria atividade e, com base nela, constituam os seus saberes-fazeres docentes, num processo contínuo de construção de novos saberes.
\end{abstract}

No que se refere à educação de surdos, a construção de novos saberes para o ensino bilíngue é fundamental, pois necessita da compreensão do professor sobre o universo da surdez, no qual o aluno surdo convive com duas línguas, no caso brasileiro, a Libras e a Língua Portuguesa na modalidade escrita. Assim, novas práticas e metodologias adequadas para o processo de ensino-aprendizagem são alguns dos muitos aspectos que mobilizam a busca por melhores caminhos na educação dos surdos.

É necessário que o professor crie um processo autônomo de busca de novos saberes, pois já não é permitido o uso de métodos tradicionais vistos, muitas vezes, pela comunidade surda, como preconceituosos e reducionistas, como o oralismo e a comunicação total para os surdos (LODI et al., 2015). O momento exige conhecimentos para o ensino bilíngue e são esses saberes que nos fazem ponderar sobre a formação do professor de alunos surdos.

A necessidade de professores com formação apropriada para o ensino de alunos surdos é fundamental, pois existem, nesse caso, peculiaridades linguísticas que precisam ser pensadas e organizadas de forma didática e metodológica, uma vez que tais particularidades linguísticas pressupõem o contato com a Libras, já que é por meio dela que os surdos podem expressar sua cultura e identidade. Porém, mais do que isto, é por meio da Libras que compreendem e se relacionam com o mundo.

É importante frisar, desse modo, a importância do processo de formação do professor e das práticas interdisciplinares voltadas para o bilinguismo, como eixo para a avaliação e reflexão sobre o processo ensino-aprendizagem e para a autopercepção do professor sobre seu trabalho docente junto a alunos surdos. 
Nesse contexto, afirma Gesser (2012, p. 24), “o professor pode refletir sua prática através da observação, da análise e da problematização constante, que por sua vez resultariam em um repertório de experiências configuradas em conhecimentos práticos". Assim, destaca-se o necessário papel autônomo do professor, mediante o qual possa desempenhar uma reflexão sobre sua própria prática docente.

Essa compreensão deve passar, inicialmente e de forma primária, pelo reconhecimento do professor de que a Libras é a língua do surdo, compondo, portanto, sua cultura e percepção de mundo, e que a Libras possui uma estrutura diferente da língua oral (KARNOPP; PEREIRA, 2015). Nesse sentido, a legislação brasileira obriga que professores tenham a disciplina de Libras em seus cursos de formação inicial (BRASIL, 2002).

Com vistas à compreensão da forma pela qual a disciplina de Libras é implementada na Universidade Federal Rural da Amazônia (UFRA), este estudo tem como objetivo principal mapear e analisar a oferta dessa disciplina nos cursos de graduação dessa IES, identificando, por meio de uma abordagem qualitativa, as características da sua oferta e trazendo uma reflexão sobre a importância da disciplina de Libras para a formação inicial do professor.

Embora sejam mencionados os cursos de bacharelado, o foco principal deste estudo são os cursos de Licenciatura. Desse modo, a pergunta norteadora desta investigação pode ser assim formulada: Quais são as características da disciplina de Libras ofertada na UFRA, sobretudo, nos cursos de Licenciatura?

A seguir, após breve contextualização do tema, será feito um histórico da UFRA, seguido dos procedimentos metodológicos da pesquisa, da apresentação dos dados e da discussão dos resultados, tirando-se daí algumas conclusões.

\section{Formação do professor: contribuições da disciplina de Libras}

A formação do professor, contextualizada e com foco no processo de ensinoaprendizagem próprio das necessidades de alunos surdos, é de fundamental importância, pois é dessa forma que acontece a mediação no desenvolvimento do processo de formação cognitiva e social destes sujeitos, além de possibilitar que eles possam construir a sua própria identidade e, dessa maneira, se posicionarem como sujeitos autônomos. Vale destacar o que enfatiza Libâneo (2011, p. 31): 
O que está em questão, portanto, é uma formação que ajude o aluno a transformar-se num sujeito pensante, de modo que aprenda a utilizar seu potencial de pensamento por meio de meios cognitivos de construção e reconstrução de conceitos, habilidades, atitudes, valores.

As reflexões sobre a formação de professores de alunos surdos e sobre suas práticas no processo de ensino-aprendizagem fazem com que se repense de que forma se pode contribuir para a aprendizagem, aquisição e convivência de duas línguas, a Libras, como primeira língua e língua de instrução e de iniciação, e a Língua Portuguesa na modalidade escrita, como segunda língua, ou seja, uma perspectiva bilíngue de educação.

O processo de ensino na perspectiva do bilinguismo para surdos necessita de uma metodologia própria, que inclua, necessariamente, a língua de sinais no processo de aprendizagem. Dessa forma, o professor de alunos surdos precisa compreender a importância da Libras para esse discente e, mais especificamente, entender como se dão os processos de ensino dessas duas línguas, sobretudo, aqueles que envolvem o aprendizado da modalidade escrita, dando ênfase ao ensino da L1 (Libras) como base para a escrita da L2. Os processos que envolvem o aprendizado da modalidade escrita como L2 devem respeitar os aspectos culturais e as particularidades das línguas sinalizadas e, também, a relação com seus pares. Nesse sentido, Karnopp e Pereira (2015, p. 125) afirmam:

O ponto de partida é um entendimento da natureza da escrita como um ato político, social, mental e linguístico. Considero a escrita como uma prática social, inserida em relações sociais de uma determinada comunidade, cada uma com suas próprias e complexas práticas convencionais e ideológicas em que o indivíduo precisa encontrar uma identidade como escritor, em que ele se sinta confidente e confortável com a mesma.

Essas reflexões estão ligadas às práticas de ensino e aos saberes docentes e pontuam aspectos educacionais no contexto escolar, como as metodologias e recursos utilizados para a aprendizagem. Entendemos que, nesse sentido, a formação do professor na educação bilíngue de alunos surdos deve focar na valorização multicultural dos discentes e na identidade desse sujeito. Lodi et al (2015, p. 54) enfatizam que:

Multiculturalismo pode ser definido de várias formas. Trata-se de estabelecer níveis de respeitabilidade e garantia de igualdade de direitos humanos às pessoas com diferentes origens, crenças, etnias, gêneros, uma convivência pacífica entre os membros pertencentes a grupos minoritários e aos grupos majoritários de uma comunidade social, sem qualquer discriminação. 
Nessa lógica, defende-se a importância do professor como mediador dos processos de ensino e de aprendizagem de alunos surdos, de forma que cabe aos profissionais a tarefa de desenvolver, especialmente nesses discentes, o pensamento autônomo, crítico e criativo, além de capacitá-los para que possam avançar em suas potencialidades, contribuindo, enfim, para sua formação. Assim, o papel do professor é fundamental para o desenvolvimento da autonomia e para a organização de estruturas próprias de pensamento. Libâneo (2011, p. 31) afirma:

Está embutida aí a ajuda do professor para o desenvolvimento das competências do pensar, em função do que coloca problemas, pergunta, dialoga, ouve os alunos, ensina-os a argumentar, abre espaço para expressarem seus pensamentos, sentimentos, desejos, de modo que tragam para aula sua realidade vivida.

Para Libâneo (2011), é certo que o professor precisa seguir as mudanças trazidas pela modernidade, assim como as mudanças que pautam e norteiam a educação, como os novos contextos sociais e políticos, os novos métodos e as novas ideologias, pois os processos de reestruturação que regem uma evolução necessitam que outras áreas os acompanhem, o que não seria diferente com a educação.

Os professores atuantes na área de educação de surdos, então, precisam aderir e criar práticas de ensino apropriadas para esses alunos, com foco no bilinguismo. $\mathrm{O}$ processo de autonomia do professor gerará estratégias de ensino para o aluno surdo, haja vista, que sua prática docente, baseada em suas observações, mediará, de forma prática, as dificuldades dos estudantes, dando ênfase ao seu canal de comunicação e auxiliando diversos estilos de aprendizagem.

Gesser (2012, p. 57, grifo do autor) enfatiza, ainda, que "cabe ao professor estar atento, não apenas para identificar tais estilos, mas também para promover situações que favoreçam um ambiente para os diferentes aprendizados". Logo, compreende-se que o docente precisa adquirir certa autonomia e buscar a motivação correta para o desenvolvimento de estratégias que favoreçam as relações em sala de aula, de forma a intermediar as diferenças.

Observa-se que, no contexto educacional que envolve a educação de alunos surdos, é imprescindível que o professor promova a autonomia no processo de mediação dos saberes. É possível, ainda, considerar o professor como mediador e o aluno como um 
aprendiz atento que observa as metodologias desenvolvidas pelo docente, identificando as peculiaridades do ensino proposto.

Por isso, a formação de professores é tão importante, para que possa trazer elementos de autonomia e prática docente coerente com a perspectiva bilíngue voltada para a educação de surdos. Conforme a legislação atual (BRASIL, 2002; 2005), essa formação tem sido garantida, em parte, pela obrigatoriedade de os professores cursarem uma disciplina de Libras durante a graduação em cursos de licenciatura, decorrendo daí a necessidade de se refletir sobre as características da oferta desta disciplina.

\section{A Universidade Federal Rural da Amazônia}

Considerando que esta pesquisa investiga a implementação da disciplina de Libras nos cursos de licenciatura da Universidade Federal Rural da Amazônia (UFRA), torna-se necessário conhecer a trajetória histórica desta instituição.

O ensino de Ciências Agrárias, no Pará, teve início no ano de 1918 quando foi criada a Escola de Agronomia do Pará, nos termos da Lei Orgânica do Centro Propagador das Ciências e de acordo com o Decreto Federal n ${ }^{\circ}$ 8319, de 20 de outubro de 1910, objetivando a educação profissional aplicada à agricultura, à zootecnia, à veterinária e às indústrias rurais (UFRA, 2016).

Em 1943, ocorreu o encerramento das atividades da Escola de Agronomia do Pará e, então, surgiu a Escola de Agronomia da Amazônia (EAA), anexa ao Instituto Amazônico do Norte (IAN), criada pelo Decreto-Lei no 8290, de 5 de dezembro de 1945, publicado em 07 de dezembro de 1945. A instalação e o efetivo exercício ocorreram em 17 de abril de 1951. Em 8 de março de 1972, foi transformada na Faculdade de Ciências Agrárias do Pará (FCAP).

Durante os 21 anos de atividades, a EAA formou 451 engenheiros agrônomos e manteve as características de escola regional, formando profissionais aptos a atuar, principalmente, na Região Norte, bem como recebeu estudantes e formou técnicos de outros países sul-americanos com área amazônica, tendo sido reconhecida como uma das principais escolas de agronomia do trópico. Em 1971, foi criado o Curso de Engenharia Florestal, reconhecido pelo Decreto no 80.030, de 27 de julho de 1977 (UFRA, 2016).

A criação da UFRA, em substituição à Faculdade de Ciências Agrárias do Pará (FCAP), aconteceu por meio da Lei $n^{\circ} 10.611$, de 23 de dezembro de 2002. A UFRA, dotada de autonomia didático-científica, administrativa e de gestão financeira e 
patrimonial, tem como missão formar profissionais de nível superior, desenvolver e compartilhar a cultura técnico-científica por meio da pesquisa e da extensão, oferecer serviços à comunidade e contribuir para o desenvolvimento econômico, social e ambiental da Amazônia (UFRA, 2016).

A UFRA é a mais antiga instituição de ensino superior em Ciências Agrárias da Amazônia e, atualmente, vem ampliando sua atuação profissional por meio da implantação de novos cursos em outros campos do saber, como os de Bacharelado em Sistemas de Informação, de Licenciatura em Ciência da Computação, de Licenciatura em Letras-Língua Portuguesa e de Licenciatura em Letras-Libras. O Curso de Letras-Libras alcançou, recentemente, nota máxima na avaliação de cursos de graduação do MEC. No ano de 2008, a UFRA foi a instituição de ensino superior com maior Índice de Qualificação do Corpo Docente (IQCD), em toda a Amazônia Legal.

Atualmente, a UFRA oferece 37 cursos de graduação, sendo trinta bacharelados e sete licenciaturas. Na área de pós-graduação, oferece cursos de mestrado e doutorado (UFRA, 2016). O Quadro 1 mostra a distribuição dos cursos oferecidos por câmpus e por tipo de curso.

Quadro 1 - Oferta de cursos de graduação da UFRA

\begin{tabular}{|c|c|c|c|}
\hline Câmpus & Licenciatura & Bacharelado & Total \\
\hline Belém & 3 & 8 & 11 \\
\hline Capanema & 1 & 5 & 6 \\
\hline Capital Poço & 1 & 4 & 5 \\
\hline Paragominas & - & 5 & 5 \\
\hline Parauapebas & - & 5 & 5 \\
\hline Tomé-Açu & 2 & 3 & 5 \\
\hline Total & $\mathbf{7}$ & $\mathbf{3 0}$ & $\mathbf{3 7}$ \\
\hline
\end{tabular}

Fonte: Dados da pesquisa.

Por este quadro, observa-se que a UFRA, atualmente, dispõe de sete cursos de licenciatura e trinta de bacharelado. A oferta desses cursos está concentrada na cidade de Belém, mas os câmpus, localizados em cidades do interior do estado, também ofertam tanto as licenciaturas como os bacharelados. Apenas os câmpus de Paragominas e Parauapebas não ofertam cursos de licenciatura. 


\section{Metodologia}

Para este estudo foi utilizada a técnica de levantamento de informações em diferentes fontes, com informações extraídas de todos os Projetos Pedagógicos dos Cursos (PPC) e de documentos exigidos pelos órgãos normalizadores do ensino superior para aprovação de cursos disponíveis no site oficial da UFRA.

$\mathrm{Na}$ identificação dos cursos que ofertam a disciplina de Libras, foram adotados os seguintes procedimentos metodológicos: 1) Levantamento de todos os cursos da UFRA; 2) Levantamentos dos cursos que ofertam a disciplina Libras; 3) Levantamento das ementas, especificamente, dos cursos de Licenciatura; 4) Análise das ementas e das referências.

O recorte recai sobre os cursos que oferecem em sua matriz curricular essa disciplina, excluindo-se os demais porque fogem ao foco deste estudo. O curso de licenciatura em Letras Libras, também, não foi incluído na pesquisa, por ser um curso de formação de professores de Libras e com carga horária integralmente específica para essa finalidade. Assim, como visto no Quadro 1, a UFRA oferta 37 cursos de graduação em seus câmpus institucionais. Desse total, quinze não apresentam a disciplina de Libras em sua matriz curricular, nem mesmo como eletiva. Assim, foram considerados como universo da pesquisa 21 cursos de graduação, sendo seis de licenciatura e quinze de bacharelado, ficando a amostra da pesquisa composta de seis cursos de Licenciatura.

Apesar da oferta da disciplina de Libras em vários cursos de bacharelado, o estudo se concentrou, sobretudo, na análise das ementas da disciplina de Libras de seis cursos de licenciatura, com destaque para a verificação das cargas horárias, dos objetivos e das referências.

O levantamento dos cursos e da oferta da disciplina de Libras foi realizado com base nas informações contidas no site oficial da UFRA. Inicialmente, foram feitas pesquisas e análises para cada câmpus da instituição, separadamente, incluindo tanto os cursos de bacharelado quanto os de licenciatura. Ao observar os dois tipos de cursos (licenciatura e bacharelado), constatou-se que nos cursos de licenciatura, conforme prevê a Lei 10.436/2002, a disciplina de Libras aparece no currículo como obrigatória, diferentemente dos cursos de bacharelado, em que figura como eletiva e com variação de carga horária.

Para as cargas horárias, as análises se basearam em como estão organizadas as aulas teóricas e práticas, o total de horas, o semestre do curso em que a disciplina é 
ofertada, se a disciplina é eletiva ou obrigatória e se é ofertada de forma presencial ou a distância. Por fim, as informações coletadas foram sistematizadas em quadros para análise de cada curso e de cada ementa.

\section{Apresentação dos dados}

Nesta seção, são apresentadas a descrição e a forma escolhida para a apresentação dos resultados encontrados na pesquisa. Inicialmente, são sistematizadas as informações referentes aos cursos que ofertam a disciplina de Libras. Na sequência, são destacados os conteúdos e objetivos das ementas, suas cargas-horárias e referências bibliográficas.

\subsection{Caracterização dos cursos que oferecem a disciplina de Libras}

Para melhor identificação dos 21 cursos que ofertam a disciplina de Libras da UFRA (licenciatura e bacharelado), as informações foram sistematizadas de modo a indicar o curso, a modalidade (presencial, híbrido, à distância, e outros), o tipo de graduação (bacharelado ou licenciatura), a oferta da disciplina de Libras, o eixo (eletiva ou obrigatória), o semestre e a carga horária. como mostra o Quadro 2.

Quadro 2 - Cursos da UFRA que oferecem a disciplina de Libras em seu currículo.

\begin{tabular}{|c|c|c|c|c|c|c|}
\hline CURSOS & $\begin{array}{l}\text { TIPO DE } \\
\text { CURSO }\end{array}$ & MODALIDADE & EIXO & PERÍODO & $\mathbf{C H}^{1} \mathbf{T}$ & $\mathrm{CHP}^{2}$ \\
\hline \multicolumn{7}{|c|}{ CÂMPUS BELÉM } \\
\hline Ciência da Computação & Licenciatura & Presencial & Obrigatória & $8^{\circ}$ & - & 68 \\
\hline Letras Português & Licenciatura & Presencial & Obrigatória & $7^{\circ}$ & 27 & 7 \\
\hline $\begin{array}{l}\text { Engenharia de Cartografia } \\
\text { e Agrimensura }\end{array}$ & Bacharelado & Presencial & Eletiva & $10^{\circ}$ & 51 & - \\
\hline \multicolumn{7}{|c|}{ CÂMPUS CAPANEMA } \\
\hline Ciências Biológicas & Licenciatura & Presencial & Obrigatória & $8^{\circ}$ & 30 & 38 \\
\hline Ciências Biológicas & Bacharelado & Presencial & Eletiva & $8^{\circ}$ & 30 & 38 \\
\hline $\begin{array}{l}\text { Engenharia Ambiental e } \\
\text { Energias Renováveis }\end{array}$ & Bacharelado & Presencial & Eletiva & $8^{\circ}$ & 51 & - \\
\hline Administração & Bacharelado & Presencial & Eletiva & $8^{\circ}$ & 30 & 38 \\
\hline \multicolumn{7}{|c|}{ CÂMPUS CAPITÃO POÇO } \\
\hline Ciência da Computação & Licenciatura & Presencial & Obrigatória & $4^{\circ}$ & - & 68 \\
\hline Engenharia Florestal & Bacharelado & Presencial & Eletiva & $8^{\circ}$ & 15 & 19 \\
\hline Sistema de informação & Bacharelado & Presencial & Eletiva & $8^{\circ}$ & 34 & - \\
\hline CURSOS & $\begin{array}{l}\text { TIPO DE } \\
\text { CURSO }\end{array}$ & MODALIDADE & EIXO & PERÍODO & CHT & $\mathbf{C H P}^{*}$ \\
\hline \multicolumn{7}{|c|}{ CÂMPUS PARAGOMINAS } \\
\hline
\end{tabular}




\begin{tabular}{|c|c|c|c|c|c|c|}
\hline Sistema de informação & Bacharelado & Presencial & Eletiva & $8^{\circ}$ & 34 & - \\
\hline Zootecnia & Bacharelado & Presencial & Eletiva & $4^{\circ}$ & 20 & 14 \\
\hline \multicolumn{7}{|c|}{ CÂMPUS DE PARAUAPEBAS } \\
\hline Administração & Bacharelado & Presencial & Eletiva & $8^{\circ}$ & $34^{3}$ & - \\
\hline Agronomia & Bacharelado & Presencial & Eletiva & $8^{\circ}$ & 30 & 38 \\
\hline Engenharia Florestal & Bacharelado & Presencial & Eletiva & $8^{\circ}$ & 30 & 38 \\
\hline Engenharia da Produção & Bacharelado & Presencial & Eletiva & $8^{\circ}$ & - & 68 \\
\hline Zootecnia & Bacharelado & Presencial & Eletiva & $4^{\circ}$ & 10 & 24 \\
\hline \multicolumn{7}{|c|}{ CÂMPUS TOMÉ-AÇU } \\
\hline Ciências Biológicas & Licenciatura & Presencial & Obrigatória & $7^{\circ}$ & 34 & 17 \\
\hline Letras Português & Licenciatura & Presencial & Obrigatória & $5^{\circ}$ & 51 & 17 \\
\hline Administração & Bacharelado & Presencial & Eletiva & $8^{\circ}$ & 30 & 38 \\
\hline Engenharia Agrícola & Bacharelado & Presencial & Eletiva & $8^{\circ}$ & 34 & - \\
\hline
\end{tabular}

Fonte: Dados da pesquisa.

Todos os cursos da UFRA, listados no Quadro 2, são presenciais. A disciplina de Libras é obrigatória em todos os cursos de licenciatura e eletiva, quando prevista, nos cursos de bacharelado. A disciplina é oferecida a partir do quarto período do curso, observando-se uma concentração no último período.

Como mostra o mapeamento (Quadros 1 e 2), quinze dos trinta cursos de bacharelado preveem a oferta da disciplina de Libras e somente o câmpus de Parauapebas oferta a disciplina em todos os seus cursos de bacharelado. Essa ausência de oferta da disciplina de forma eletiva em cursos de bacharelado parece estar em desacordo com o que preconiza o artigo $3^{\circ}$ e parágrafo $2^{\circ}$ do Decreto 5626/2005, ao afirmar que: "a Libras constituir-se-á em disciplina curricular optativa nos demais cursos de educação superior e na educação profissional, a partir de um ano da publicação deste Decreto" (BRASIL, 2005, p. 1).

Quanto à carga horária da disciplina de Libras, é possível observar que varia entre 34, 51 ou 68 horas. A maioria dos cursos de licenciatura trabalha com 68 horas, enquanto nos cursos de bacharelado prevalece, na maioria dos cursos, a carga horária de 34 horas. Uma carga horária tão baixa só se torna compreensível se considerarmos os objetivos diferentes dos cursos. No entanto, pode-se questionar se isso favorece o aprendizado de uma língua como a Libras (PAIVA; CHAVEIRO; FARIA, 2018).

$\mathrm{Na}$ análise dos dados, observou-se, ainda, que, não há, aparentemente, diretrizes institucionais que padronizem a oferta da disciplina de Libras, quanto à sua duração, distribuição de carga horária entre aulas teóricas e práticas, ementas, objetivos e 
referências, básicas e complementares, não havendo diferenciação significativa entre as propostas dos cursos para esta disciplina.

Os dados apresentados nos próximos tópicos dizem respeito unicamente aos seis cursos de licenciatura que oferecem a disciplina de Libras, por ser este tipo de curso diretamente voltado para a formação do professor na perspectiva de prepará-lo para uma futura atuação docente junto a alunos surdos.

\subsection{Organização da carga horária nos cursos de licenciatura da UFRA}

Apenas um curso de licenciatura, o de Letras Português, do câmpus Belém, oferta a disciplina de Libras com carga horária de 34 horas. Essa carga horária é menor quando comparada às cargas horárias dos demais cursos de licenciatura, que ofertam a disciplina com 68 horas. Trata-se, portanto, de uma única disciplina no currículo com carga horária, a nosso ver, modesta. Aqui há um ponto sobre o qual as instituições e as políticas educacionais brasileiras deveriam refletir.

Paiva, Chaveiro e Faria (2018, p. 72) questionam sobre a disposição da carga horária da disciplina de Libras e ressaltam: "Parece-nos evidente a impossibilidade de que alguém consiga dominar uma língua em tão curto espaço de tempo [...] ainda mais no caso de uma língua pertencente a uma modalidade diferente daquela usada pelo aprendiz".

Ao analisarmos a distribuição da carga horária (Quadro 2) de todos os cursos, de licenciatura e bacharelado, identificamos que onze cursos tendem a privilegiar maior carga horária para as aulas práticas, o que consideramos ser condizente com a natureza da disciplina, enquanto que nos outros dez a disciplina possui mais horas para estudos teóricos.

No que se refere aos cursos de licenciatura, metade tem distribuição de maior quantidade de horas teóricas. Os dois cursos de Letras Português (câmpus Tomé-Açu e Belém) e um curso de Ciências Biológicas (câmpus Tomé-Açu) ofertam a disciplina de forma teórica na maior parte das horas. Vale analisar esse dado criticamente e recuperar o que trazem os resultados de Paiva, Chaveiro e Faria (2018, p. 77) sobre a opinião dos seus participantes pesquisados: "a carga horária e o pouco conhecimento prático obtido foram destacados como pontos negativos". 


\title{
4.3 Ementas da disciplina de Libras dos cursos de licenciatura da UFRA
}

As ementas contemplam, basicamente, os mesmos tópicos em todos os cursos, com pequenas nuances que as diferenciam. Observou-se que, na UFRA, a disciplina de Libras tem somente dois tipos de ementas para todos os seus cursos (licenciatura e bacharelado). Três cursos de licenciatura ofertados nos câmpus de Capitão-Poço, Capanema e Belém (Ciências da Computação e Ciências Biológicas) apresentam a seguinte ementa:

\begin{abstract}
A cultura surda. O cérebro e a língua de sinais. Processos cognitivos e linguísticos. Tópicos de linguística aplicados à língua de sinais: fonologia, morfologia e sintaxe. Uso de expressões faciais gramaticais (declarativas, afirmativas, negativas, interrogativas e exclamativas). Alfabeto digital e número. Vocabulário (família, pronomes pessoais, verbos e etc.) (UFRA, 2017a, p. 61).
\end{abstract}

Outros três cursos de licenciatura dos câmpus de Tomé-Açú e Belém (Letras Português, Ciências Biológicas e Ciência da Computação) apresentam outra proposta de ementa:

\begin{abstract}
Conceito de Libras, fundamentos históricos da educação dos surdos. Legislação específica. Aspectos linguísticos, clínicos e educacionais e sócios antropológicos da surdez. O cérebro e a língua de sinais. Processos cognitivos e linguísticos. Tópicos de linguística aplicados à língua de sinais: fonologia, morfologia e sintaxe. Uso de expressões faciais gramaticais (declarativas, afirmativas, negativas, interrogativas e exclamativas). Alfabeto digital e número. Vocabulário (material escolar, aninais, cores, família, pronomes pessoais, demonstrativos, verbos de locação entre outros) (UFRA, 2017b, p. 97).
\end{abstract}

Interessante perceber que as ementas analisadas trazem a proposta de ensinar como a cultura surda se manifesta. Porém, a primeira ementa tem um foco maior na aprendizagem da língua, a Libras, incluindo expressões faciais, vocabulário básico e estudos linguísticos. E a segunda ementa tem um foco linguístico, político e cultural.

\subsection{Referências das disciplinas de Libras dos cursos de licenciatura da UFRA}

Em relação às referências, elas estão divididas em básicas e complementares. Chama atenção, contudo, o fato de constarem nas referências apenas obras no formato de livros. Não há registro de nenhum artigo de periódicos científicos, que, geralmente, são mais recentes e atualizados e, também, não há referência a materiais didáticos em outras mídias, como vídeos, e-books, aulas em vídeos ou matérias disponíveis na internet. 
Apenas seis obras constituem as referências básicas da disciplina de Libras em todos os cursos de licenciatura da UFRA. A obra Língua Brasileira de sinais, de Karnopp e Quadros (2004), consta das referências básicas da disciplina de Libras em todos os cursos. Outras obras, como Surdez e bilinguismo, de Fernandes (2005); Libras? Que língua e essa?: crenças e preconceitos em torno da língua de sinais e da realidade surda, de Gesser (2009); Intérprete de Libras: em atuação na educação infantil e no ensino fundamental, de Lacerda (2009); Coleção aprendendo LSB, de Pimenta (2000) e A surdez: um olhar sobre as diferenças, de Skliar (1998) completam as referências básicas. Em que pese se tratar de obras importantes sobre a temática do ensino para surdos, algumas foram publicadas há mais de quinze anos, notando-se a ausência de fontes com publicação mais recente e que reflitam o estado da arte sobre o conhecimento da área.

Observou-se, ainda, que a maior parte das referências é voltada para a parte teórico-reflexiva, porém, as disciplinas de Libras são ofertadas com carga horária maior para as práticas da disciplina, sugerindo um déficit na organização da ementa. Treze

diferentes obras constituem as referências complementares de todos os cursos de licenciatura e a obra mais recorrente é Surdez: processos educativos e subjetividade, organizada por Lacerda e Góes (2000), indicada nos seis cursos de licenciatura analisados e encontrada em alguns cursos de bacharelado. A maioria das demais fontes se repete em até três cursos, indicando que não há uma variedade muito grande de fontes a serem consultadas sobre o tema ou que os professores da disciplina estão limitados a um conjunto restrito de obras tidas como clássicas. Quanto à atualidade das obras complementares, praticamente todas foram publicadas há mais de quinze anos e algumas há mais de vinte anos, o que leva ao questionamento sobre a atualização do conhecimento na área de ensino de Libras.

\section{Discussão dos resultados}

É mediante a organização curricular por disciplinas que, muitas vezes, professores e alunos conseguem desenhar o desenvolvimento da aprendizagem, com auxílio de novas práticas docentes e com novas atitudes dos discentes, como afirma Libâneo (2011, p. 30):

O ensino exclusivamente verbalista, a mera transmissão de informação, a aprendizagem entendida somente como acumulação de conhecimentos, não subsistem mais. Isso não quer dizer abandono dos conhecimentos sistematizados da disciplina nem da exposição de um assunto. 
Nesse sentido, defende-se a importância da formação do professor e do processo de ensino-aprendizagem. Cabe aos profissionais da educação a tarefa de desenvolver nos alunos o pensamento autônomo, crítico, criativo e capacitá-los para que possam avançar em suas potencialidades.

Para alcançar isso, no que se refere à disciplina de Libras, faz-se aqui uma reflexão sobre a necessária integração com outras disciplinas do próprio curso de Licenciatura. Pimenta e Anastasiou (2014, p. 226) afirmam que:

\begin{abstract}
A integração das disciplinas curriculares pode ser efetivada mediante uma revisão e reestruturação geral, quando ocorre alteração curricular de fato e de direito, ou pode comportar processos de apropriações sucessivas entre as disciplinas, mantendo ainda uma organização interdisciplinar, porém pautada por alguns princípios integrativos, coletivamente identificados.
\end{abstract}

O nosso estudo, ao analisar as ementas, bibliografias e cargas horárias da disciplina de Libras, não permite identificar esse aspecto da estruturação curricular de cada curso, não explicitando se há, ou não, uma relação didática com outras disciplinas. Consideramos que estudos dessa natureza se fazem necessários.

Nessa perspectiva, reforça-se, neste artigo, que o aluno surdo precisa ser inserido como um ser pensante em uma sociedade majoritariamente ouvinte, para poder atuar como sujeito da sua própria história, sem a necessidade de que falem ou decidam por ele, pois o ensino deve promover o seu desenvolvimento, transformando os seus conhecimentos cotidianos em conhecimentos científicos. Nesse aspecto, é de asseverar a importância e o papel da formação do professor (GESSER, 2012).

Acredita-se, que a disciplina de Libras, com aplicação no cotidiano escolar, pode contribuir para reestruturar a prática de ensino e, também, possibilitar ambientes de aprendizagem adequados aos surdos, a fim de proporcionar-lhes a oportunidade de desenvolver atividades que os desafiem a se tornarem autônomos.

Pelos resultados da pesquisa, percebe-se que a UFRA está parcialmente de acordo com as políticas para o ensino de Libras, no que se refere à Lei 10.436/02 e o Decreto $5.626 / 05$, os quais dispõem sobre as perspectivas de ensino da Libras e dão outras disposições.

A implementação da disciplina de Libras na UFRA pode estar sendo feita com vistas ao processo de compreensão do sujeito surdo e à expectativa de atuação dos profissionais formados pela instituição na sociedade. Porém, estudos já mencionam que 
carga horária muito reduzida pode comprometer essa meta e proposta (GUARINELLO et al., 2012; IACHINSKI, 2017; PAIVA, CHAVEIRO e FARIA, 2018)

\section{Considerações finais}

Este estudo poderá contribuir para a compreensão do processo de implementação da disciplina de Libras nas instituições de ensino superior, em geral, e mais especificamente, na UFRA, destacando-se que poucas são as pesquisas nessa temática.

Sobre as questões mais recorrentes pode-se afirmar que alguns cursos ofertam a disciplina de Libras com uma carga horária baixa, como os cursos que ofertam a disciplina com 34 horas de duração, tornando o aprendizado de uma língua pouco viável. Ainda não há estudos que demonstrem qual seria a carga horária ideal para a disciplina de Libras nas licenciaturas, mas algumas pesquisas (GUARINELLO et al., 2012; IACHINSKI, 2017) enfatizam que uma única disciplina não é o suficiente.

Nos cursos de licenciatura, observa-se que são implementadas cargas horárias mais extensas, porém, as ementas se repetem nos cursos, apresentam apenas pequenas variações e compartilham as mesmas referências. Estes aspectos indicam a falta de atenção que deveria ser dispensada à região geográfica onde o curso acontece, a cada curso ou área de formação e ao conteúdo de Libras mais pertinente a cada realidade.

A implementação da disciplina de Libras na UFRA, sobretudo nos cursos de formação de professores, mostra que a instituição está em desenvolvimento, se esforçando para atender à legislação no que se refere ao processo de inclusão e educação bilíngue, pois todos os câmpus têm pelo menos um curso em que é ofertada a disciplina como eletiva ou obrigatória.

O papel da formação do professor deve ser compreendido de forma significativa para a aprendizagem do aluno surdo, pois as práticas metodológicas de ensino do docente são decisivas para o desenvolvimento desse estudante. Nesse sentido, os estudos teóricos indicam que a disciplina de Libras se torna imprescindível para a formação do educador, pois os conhecimentos básicos dessa língua podem auxiliar na aplicação das metodologias de ensino quando da existência de alunos surdos.

O surdo necessita passar por experiências que o auxiliem a desenvolver suas capacidades, tanto de comunicação quanto de cognição, sendo um direito seu desfrutar e viver o processo de educação bilíngue. Nesse contexto, percebe-se o quão importante é o 
processo de implementação da disciplina de Libras, seja na formação inicial, seja na formação continuada do professor.

Cabe indicar a necessidade de estudos futuros sobre a aprendizagem dos estudantes dessa disciplina e, ainda, sobre a metodologia de ensino que está sendo empregada pelos professores responsáveis por essa disciplina. Assim, o professor poderá ter uma visão mais completa e que contribua com a estratégia e a efetividade da disciplina de Libras nos cursos de Licenciatura da UFRA e, sobretudo, professores e alunos irão compreender de que forma está contribuindo efetivamente com a formação de professores na instituição.

\begin{abstract}
This work is a mapping of the implementation of the subject of Brazilian Sign Language (Libras) at the Universidade Federal Rural da Amazônia (UFRA), with the aim of investigating how the subject is offered in the undergraduate teacher training courses of that institution. Aiming to reflect on the subject of Libras and its contribution to the training of the teacher, we analyzed the syllabus, the workload, and the references present in the Pedagogical Projects of the undergraduate courses at the UFRA. Data collection was done by searching the institution's official website. The results show that the undergraduate courses offer the subject of Libras as mandatory and with extended workload in relation to the bachelor's courses, which offer the subject as elective and with a smaller workload. However, research has shown that there is no significant variation in syllabus content between bachelor's and teacher training courses, except for the specificities of each.
\end{abstract}

Keywords: Libras. Subject. Undergraduate. Teacher training.

\title{
Referências
}

ALMEIDA, Maria Isabel de. Formação do professor do ensino superior: desafios e políticas. São Paulo: Cortez, 2012.

BRASIL. Ministério da Educação. Lei n. 10.436, de 24 de abril de 2002. Dispõe sobre a Língua Brasileira de Sinais - Libras e dá outras providências. Disponível em: http://portal.mec.gov.br/arquivos/pdf/lei10436.pdf. Acesso em: abr. 2020.

Decreto No 10.611, de 23 de dezembro de 2002. Dispõe sobre a transformação da Faculdade de Ciências Agrárias do pará em Universidade Federal Rural da Amazônia e dá outras providências. Disponível em: http://www.planalto.gov.br/ ccivil_03/leis/2002/110611.htm\#: :text=LEI\%20No\%2010.611\%2C\%20DE\%2023\%20 
DE\%20DEZEMBRO\%20DE\%202002.\&text=Disp\%C3\%B5e\%20sobre\%20a\%20trans forma $\% \mathrm{C} 3 \% \mathrm{~A} 7 \% \mathrm{C} 3 \% \mathrm{~A} 3 \mathrm{o} \% 20 \mathrm{da}$, Art. Acesso em: abr. 2020.

Decreto $N^{\circ}$ 5.626, de 22 de dezembro de 2005. Regulamenta a Lei $n^{\circ} 10.436$, de 24 de abril de 2002, que dispõe sobre a Língua Brasileira de Sinais - Libras, e o art. 18 da Lei $\mathrm{n}^{\circ}$ 10.098, de 19 de dezembro de 2000. Disponível em: <http://www.planalto. gov.br/ccivil_03/_ato2004-2006/2005/decreto/d5626.htm>. Acesso em: abr. 2020.

GESSER, Audrei.. O ouvinte e a surdez: sobre ensinar e aprender a Libras. São Paulo: Ed. Parábola, 2012.

GUARINELLO, Ana Cristina et. al. A disciplina de Libras no contexto de formação acadêmica em fonoaudiologia. Rev. CEFAC, São Paulo, v. 15. n. 2, 2012. Disponível em: https://www.scielo.br/pdf/rcefac/2012nahead/159-11.pdf. Acesso em: mai. 2020.

IACHINSKI, Luci Teixeira. A percepção de acadêmicos de licenciatura a respeito da disciplina Libras. 2017. 100f. Dissertação (Mestrado em Distúrbios da Comunicação) - Universidade Tuiuti do Paraná, Curitiba, 2017.

KARNOPP, Lodenir Becker; PEREIRA, Maria Cristina da Cunha. Concepções de leitura e de escrita na educação de surdos. Porto Alegre: Ed. Mediação, 2015.

LIBÂNEO, José Carlos. Adeus professor, adeus professora? Novas exigências educacionais e profissão docente. São Paulo: Cortez, 2011.

LODI, Ana Claudia Balieiro et al. Letramento, bilinguismo e educação de surdos. 2. ed. Porto Alegre: Ed. Mediação, 2015.

PAIVA, G. X. S.; FARIA, J. G.; CHAVEIRO, N. O ensino de Libras nos cursos de formação de professores: desafios e possibilidades. Rev. Sinalizar, Goiânia, v. 3, n. 1, p. 68-80, jan. / jun., 2018. Goiânia, 2018. Disponível em: https://www.revistas.ufg.br/ revsinal/article/view/53145/25772. Acesso em: 08 out.2020.

PIMENTA, Selma Garrido; ANASTASIOU. Léa das Graças Camargos. Docência no ensino superior. 5. Ed. São Paulo: Ed. Cortez, 2014.

UFRA. Universidade Federal Rural da Amazônia. Histórico da instituição. Belém-PA, 2016. Disponível em: https://novo.ufra.edu.br/index.php?option=com_content\&view $=$ article $\&$ id=76\&Itemid=268. Acesso em: 20 jul. 2020 .

UFRA. Universidade Federal Rural da Amazônia. Projeto pedagógico do curso de Licenciatura em Ciências Biológicas. Capanema-PA, 2017a. Disponível em: https://capanema.ufra.edu.br/antigo/attachments/article/23/PPC\%20Biologia\%20Licenc iatura\%20Capanema\%20-\%20Atual\%202018.pdf. Acesso em: 20, jul. 2020.

UFRA. Universidade Federal Rural da Amazônia. Projeto pedagógico do curso de Licenciatura em Ciências Biológicas. Tomé-Açú-PA, 2017b. Disponível em: 
https://tomeacu.ufra.edu.br/images/Biologia/PPC_Cincias-Biolgicas_-Tom-Au.pdf. Acesso em: 20, jul. 2020.

\section{Notas}

\section{${ }^{1}$ CHT: Carga Horária Teórica \\ ${ }^{2}$ CHP: Carga Horária Prática}

${ }^{3}$ Apesar da carga horária desta disciplina ser de 34 horas, no Projeto Pedagógico do Curso (PPC), no ementário do mesmo documento, identificamos a informação de 30 horas para teórica e 38 horas para prática, o que se deve, possivelmente, a um erro no registro da ementa. 